12 | Saiful Arifin : Desensitization with Self-Antigen dsDNA Inhibits B and T-cell Functions by Modulating Treg

\title{
Desensitization with Self-Antigen dsDNA Inhibits B and T-cell Functions by Modulating Treg as Regulator Immune System in Pristane-induced Lupus Mice Model
}

\section{S Arifin ${ }^{1 *}$, K Handono ${ }^{2}$, S Poeranto ${ }^{3}$, N Nurdiana, ${ }^{4}{ }^{\text {K D D Hartanti }}{ }^{1}$, T M Albaar ${ }^{1}$, R Gumilang $^{1}$ and N A Dharmesta ${ }^{1}$}

\author{
${ }^{1}$ Master Degrees of Biomedical Sciences, Faculty of Medicine Universitas Brawijaya, \\ Malang, Indonesia \\ ${ }^{2}$ Department of Clinical Pathology, Faculty of Medicine Universitas Brawijaya, Malang, \\ Indonesia \\ ${ }^{3}$ Department of Clinical Parasitology, Faculty of Medicine Universitas Brawijaya, Malang, \\ Indonesia \\ ${ }^{4}$ Department of Pharmacology, Faculty of Medicine Universitas Brawijaya, Malang, \\ Indonesia \\ *Corresponding author: akulahperubahan24 @gmail.com
}

\begin{abstract}
The aim of this study was to develop a novel therapeutic method for improving immune system regulation in SLE using escalating dose self-antigen dsDNA immunotherapy. Methods: Female Balb/c mice were given a single intraperitoneal injection of $0.5 \mathrm{ml}$ pristane.. Starting at 12 weeks after injection,. the mice were evaluated for clinical and serological manifestations. Mice with lupus signs (PIL mice) were divided into four groups; positive control group, PIL A $(0.01 \mu \mathrm{g} / \mathrm{ml}, 0.1 \mu \mathrm{g} / \mathrm{ml}, 1 \mu \mathrm{g} / \mathrm{ml}$ ) EDI dsDNA, PIL B $(0.1 \mu \mathrm{g} / \mathrm{ml}, 1 \mu \mathrm{g} / \mathrm{ml}, 10 \mu \mathrm{g} / \mathrm{ml})$ EDI dsDNA, and PIL C $(1 \mu \mathrm{g} / \mathrm{ml}, 10 \mu \mathrm{g} / \mathrm{ml}, 100$ $\mu \mathrm{g} / \mathrm{ml})$. EDI dsDNA were administered once every week in consecutively. The doses would increase every week. dsDNA were complexed with the cationic polyethylenimine (PEI) before injection. Samples were analyzed for autoantibodies levels (dsDNA, ANA) and ,TGF- $\beta$ cytokine from serum using ELISA and T-Reg, mature dendritic cells from spleen using flowcytometry.. Results: Escalating dose antigen spesific immunotherapy with self-antigen dsDNA significantly decreased ANA ( $\mathrm{p}=0.02)$, anti-dsDNA ( $\mathrm{p}=0.03)$, dendritic cell mature $(\mathrm{p}=0.02)$ compare to positive control, and not significantly decreases Th17 cells $(\mathrm{p}=0,18)$ but the result tend to get lower. Desensitization using self-antigen dsDNA was increased T-reg proliferation $(\mathrm{p}=0.00)$ and level of TGF- $\beta(\mathrm{p}=0.03)$ significantly compare to positive control. Conclusion: Desensitization using self-antigen dsDNA coupled to PEI was able to modulate T-Reg as a regulator immune respon and inhibit B and $\mathrm{T}$ cell functions in lupus mice model.
\end{abstract}

Keywords: Systemic Lupus Erythematosus, dsDNA, escalating dose, tolerance, Treg INTRODUCTION

Systemic Lupus Erythematosus (SLE) is an autoimmune disease multi-systemic connective tissue inflammatory disease with high mortality and morbidity (Kessenbrock et al., 2009).
Previous research at dr. Saiful Anwar Hospital Malang reported that SLE patient life expectancy is very low with severe clinical manifestations (Kalim, 1996). This proves that 
SLE is a dangerous disease and quite common in Indonesia. In addition, the disease is often suffered by women of reproductive age and most of the women has decreased productivity and ability to perform daily activities.

The pathogenesis of SLE is not clearly known until now, but it has been known that the presence of abnormalities of the immune system is caused by a disruption of T-regulator cell function (Treg) in regulating the immune response and this has an impact on hyperactivation of various helper $\mathrm{T}$ cells (Th). Th cells, such as Th1, Th2, and Th17, will be activated by dendritic cells (DC) or other APC cells and stimulates inflammatory. Dendritic cells can recognize different types of self antigen, especially dsDNA which has an important role in the pathogenesis of SLE, and through activation of $B$ cells will stimulate the formation of antibodies against self-antigen dsDNA. The presence of these pathogenic autoantibodies will result in tissue damage due to immune complex deposition. In addition, various cytokines such as IL-1, IL-6, IFN $\gamma$ and IL-17 that act as inflammatory mediators were increased, whereas anti-inflammatory cytokines such as TGF- $\beta$ and IL-10 were decreased. This cytokine imbalance plays a significant role in the pathogenesis of SLE (Pathak and Mohan, 2011).

SLE standard therapy which is the administration of immunosuppressant and steroid medications have not shown satisfactory results. Furthermore, steroid administration for long period of time may cause many problems in SLE patients (Pathak and Mohan, 2011). Another method of therapy that is now also being developed for autoimmune patients is the administration of vaccines. A previous study by Uyttenhove (Uyttenhove and Snick, 2006) showed that by administering $10 \mu \mathrm{g}$ of IL-17A kinoid vaccine conjugated to OVA was able to induce protective antibodies against IL-17A in autoimmune encephalitis. The anti-IL-17A antibody was also shown to induce significant neutralization of IL-17A cytokines. Research on the use of IL-17A kinoid vaccine in Lupus model mice previously performed by Kusworini (Handono et al., 2016) showed that administeration of $1 \mu \mathrm{g}$ of IL-17A have been able to induce the formation of protective antiIL-17A antibodies and improve immune response.

The development of elicit dose specific antigen immunotherapy with gradual selfantigen administration has been tried in multiple-sclerosis autoimmune models. The study used schwan cell self-antigens, the MBP (Myelin Basic Protein), and resulted in a significant reduction in proinflammatory cytokines and showed the return of tolerance mechanisms (Sakaguchi et al., 2001). Based on the success of Yuan et al's research, the question arises whether self-antigens dsDNA can be used as immunotherapy in autoimmune disease. The aim of this study is to explore the use of selfantigen dsDNA, as an inducer of immune system tolerance, in improving immune system regulation and restoring the mechanism of selfantigen tolerance in SLE disease. This research that will be conducted within two years is expected to observe the potential, effectiveness, and safety of escalating dose self-antigen dsDNA immunotherapy in pristane-induced lupus mice model. 


\section{METHODS}

Mice

9-10-weeks-old Female Balb/c mice were obtained from Veterinarian Center (Surabaya, Indonesia). All mice were housed at Pharmacology Laboratory, Faculty of Medicine Brawijaya University, given for water and food ad libitum. All experimental protocols described in this study were approved by the Ethical Committee for Animal Experimentation of Faculty of Medicine Brawijaya University.

Preparation of immunogen

ds-DNA was isolated from healthy mice blood serum. Lytic cell solution is added to lyse the red blood cells. Centrifugation is done for 2 minutes, the supernatant is removed, and then vortexed. $300 \mu \mathrm{L}$ of lytic nucleic solution was added. The protein precipitation solution is added, vortexed, then centrifuged for 3 minutes till the dark-brown pellet appear. The supernatant then transferred to a tube containing isopropanol $300 \mu \mathrm{L}$. Reverse the tube to mix the solution and then centrifuged for 1 minute. Remove the supernatant and add $300 \mu$ of ethanol 70\%. Turn the tube back and forth slowly and centrifuge at 13.500rpm for 1 minute. Ethanol is taken slowly without the pellets and tubes was reversed to dry, then add a DNA rehydration solution.

Induction and treatment of pristane-induced lupus mice model

Balb/c female mice 6-8 weeks old and 20-30 grams body weight separated randomly to negative control group (healthy mice) and pristane induced lupus (PIL) mice group. PIL mice groups were injected $0.5 \mathrm{cc}(782 \mu \mathrm{g} / \mathrm{ml})$ pristane intraperitoneally. Twelve weeks after the injection of pristane, the mice were evaluated for clinical and serological manifestations (anti-dsDNA levels). Mice with lupus signs or PIL mice were divided into four groups; positive control group: PIL mice without EDI dsDNA therapy, treatment A: PIL mice with EDI dsDNA therapy dose I (0.01 $\mu \mathrm{g} / \mathrm{ml}, 0.1 \mu \mathrm{g} / \mathrm{ml}, 1 \mu \mathrm{g} / \mathrm{ml})$ were administered once a week consecutively, treatment B: PIL mice with EDI dsDNA therapy dose dose II (0.1 $\mu \mathrm{g} / \mathrm{ml}, 1 \mu \mathrm{g} / \mathrm{ml}, 10 \mu \mathrm{g} / \mathrm{ml}$ ) were administered once a week consecutively and treatment C: PIL mice with EDI dsDNA therapy dose III (1 $\mu \mathrm{g} / \mathrm{ml}, 10 \mu \mathrm{g} / \mathrm{ml}, 100 \mu \mathrm{g} / \mathrm{ml}$ ) were administered once every week in consecutively..

Injection

The invivo-jetPEI reagent is dissolved in 5\% glucose with sterile water solvent at halfvolume injection. Vortex slowly and spin down. Add the solution entirely to the ds-DNA solution. Vortex slowly and spin down. Incubation is performed for 15 minutes at room temperature until the solution becomes stable. DsDNA is injected intraperitoneally according to the dose of each treatment group.

Measurement of antibody levels against self antigen-dsDNA

Measurement procedure is done by coating antigen 1:20 in ELISA tube, incubated overnight at $40 \mathrm{oC}$, then washed with PBS-T. BSA $1 \%$ was added for blocking. Washed again with PBS-T. Primary antibodies (serum) were diluted by 1:500 in PBS, $100 \mu \mathrm{m}$ was added in the tubes then incubated for 1 hour. The tubes were washed again with 300 ul of PBS-T $0.2 \%$ for 3 times. Secondary antibody labeled- 
enzyme (anti mouse IgG) 1:1000 was added to the tube and then incubated for 1 hour. Washed with PBS-T 0.2\%. SA-HRP 1:1000 was added and incubated for 1 hour. Washed with PBS-T $0.2 \%$. TMB substrate (sureblue) was added and incubated 30 minutes. Without removing the Sureblue TMB, the reaction is stopped by addition of $1 \mathrm{~N} \mathrm{HC}$ and then incubated for 15 minutes. The measurement was read using ELISA reader $(\lambda=450 \mathrm{~nm})$. Anti dsDNA levels are shown in $\mathrm{ul} / \mathrm{mL}$.

\section{Measurement of Dendritic Cell Activity}

Blood CD11b markers were measured using flowcytometry from peripheral blood mononuclear cells (PBMCs). Ficoll hypaque solution is used to separate PBMCs from whole blood. The results of PBMC isolation and homogenization of hepatic tissue were centrifuged to obtain cell pellets. Cell pellets were washed with cell staining buffer (CSB) and then stained using antibodies for cell surface markers which is CD11b-FITC which has been diluted with CSB with a certain ratio. The solution then incubated for 20 minutes at room temperature in dark place. The cell pellets that have been colored by the antibodies are

\section{RESULTS}

Desensitization of dsDNA reduce serum ANA autoantibody level

Our investigation was to assess the ability desensitization of the dsDNA peptide inhibit ANA autoantibody production. Serum ANA levels were slightly higher in $\mathrm{K}+(30.40 \pm 0.5)$ compared to K- $(26.60 \pm 2.80, p=0.77)$. Serum ANA levels in A $(24.60 \pm 3.49, \mathrm{p}=0.24)$ were slightly lower but not significantly different compared to $\mathrm{K}+$. Significantly lower levels of added by CSB as needed and then analyzed using flowcytometry.

Measurement of cytokine levels produced by Th cells

Th1, Th2, Th17, and Treg cells that have been induced were measured for the levels produced cytokines. Cytokines were measured from plasma supernatants. Measured cytokines include: IFN- $\gamma$, IL-5, IL-17A, and TGF- $\beta 1$. The levels of cytokine were measured using ELISA. Data Collection and Analysis Procedures.

The results of measured parameters were analyzed statistically by using the IBM SPSS Statistics 20 program with a significance level of $0.05(p=0.05)$ and confidence level of $95 \%$ $(\alpha=0.05)$. The steps of hypotetic comparative and correlative testing are normality test, variance homogeneity test, One-Way ANOVA test, Post hoc test, and Pearson correlation test and Regression test.

Ethiccal Aproval

All experimental protocols described in this study were approved by the Ethical Committee for Animal Experimentation of Faculty of Medicine Brawijaya University (No. 336/EC/KPEK/09/2016.

serum anti-dsDNA levels were found in B (21.6 $\pm 2.25, \mathrm{p}=0.02$ ) compared to $\mathrm{K}+$ Serum ANA levels in $\mathrm{C}(22.97 \pm 2.24, \mathrm{p}=0.38)$ were slightly lower but not significantly different compared to $\mathrm{K}+$ (figure 1).

Desensitization of dsDNA reduce serum dsDNA autoantibody level

Our investigation was to assess the ability of the dsDNA peptide to inhibit dsDNA autoantibody production. Serum dsDNA autoantibody levels 
were significantly higher in $\mathrm{K}+(63.4 \pm 40.47)$ compared to K- $(7.85 \pm 5.00 \mathrm{p}=0.03)$. Serum dsDNA autoantibody levels in A $(61.70 \pm$ 21.38, $\mathrm{p}=1.00$ ) were slightly lower but not significantly different compared to $\mathrm{K}+$. Serum dsDNA autoantibody levels in B $(47,28 \pm 13.2$, $\mathrm{p}=0.86$ ) were slightly lower but not significantly different compared to $\mathrm{K}+$.Lowest levels of serum dsDNA autoantibody were found in $C(5.65 \pm 4.67, p=0.03)$ significantly different compared to $\mathrm{K}+$ (figure 2 )

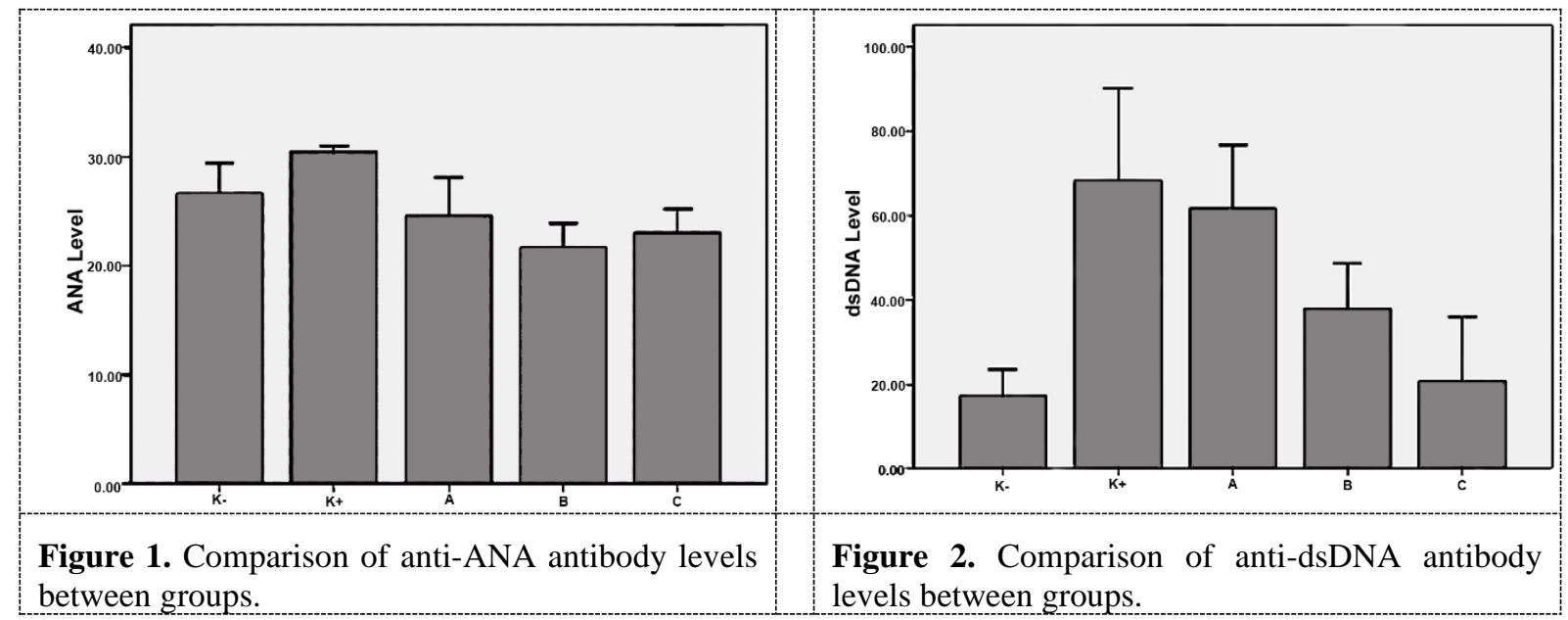

Desensitization of dsDNA peptide reduce percentage of Dendritic cell maturation Our investigation was to assess the ability of the dsDNA peptide to reduce dendritic cell maturation. Assesment of dendritic cell Blood $\mathrm{CD} 11 \mathrm{~b}$ markers were measured using flowcytometry from peripheral blood mononuclear cells (PBMCs). The percentages of matur dendritic cells were measured from the cells which positively expressed CD4 and
CD11b-FITC. As shown in figure 3, the percentages of mature dendritic cells in $\mathrm{K}$ group $(1.12 \pm 0.24)$ was significantly lower compared to $\mathrm{K}+(2.43 \pm 0.83, \mathrm{p}=0.11)$. The percentage of mature dendritic cells between group A $(0.75 \pm 0.55 ; \mathrm{p}=0.00), \mathrm{B}(1.13 \pm 1.06$; $\mathrm{p}=0.01)$, and $\mathrm{C}(1.22 \pm 0.55 ; \mathrm{p}=0.02)$ significantly different compared to $\mathrm{K}+$ (figure 3)

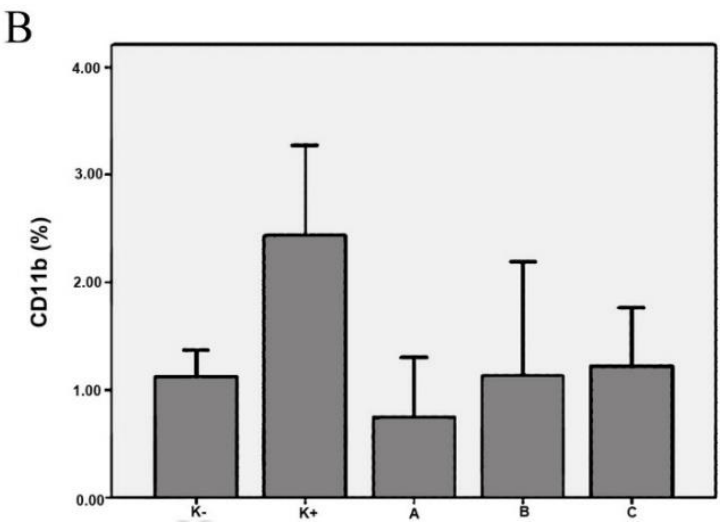

Figure 3. Representative of flow cytometric dot plot analysis between groups for mature dendritic cells percentages, mature dendritic cells were measured in the upper right quadrant expressing CD11b-FITC + 
Desensitization of dsDNA peptide reduce

Th17 cell proliferation

The representative dot plots of Th17 cells in flowcytometry analysis were shown in figure 4A. The percentages of Th17 cells were measured from the cells which positively expressed CD4 and IL-17A (upper right quadrant in the dot plot). As shown in figure 4B, the percentages of Th17 cells in K- group (3.79

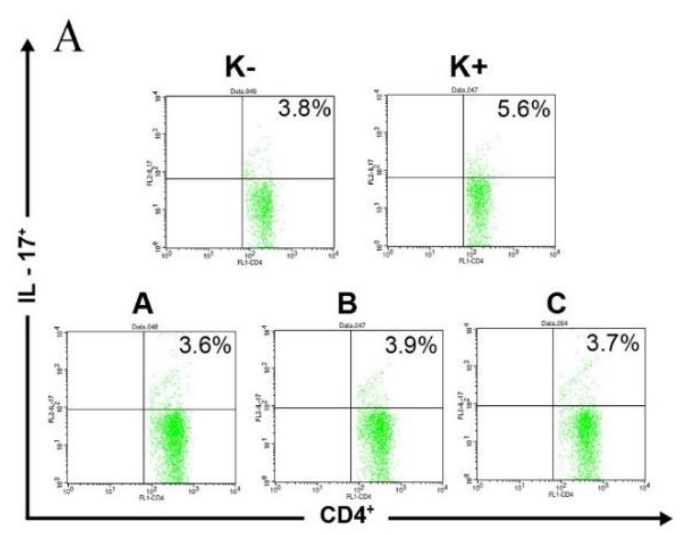

$\pm 0.44)$ was not significantly lower compared to $\mathrm{K}+(5.62 \pm 0.85, \mathrm{p}=0.21)$. Also, there was slightly lower level of Th17 cells between group A (3.62 $\pm 0.37 ; \mathrm{p}=0.18), \mathrm{B}(3.86 \pm 1.03$; $\mathrm{p}=0.41)$ and $\mathrm{C}(3.73 \pm 0.49 ; \mathrm{p}=0.216)$ compared to $\mathrm{K}+$ but not significant. but the result tend to get lower

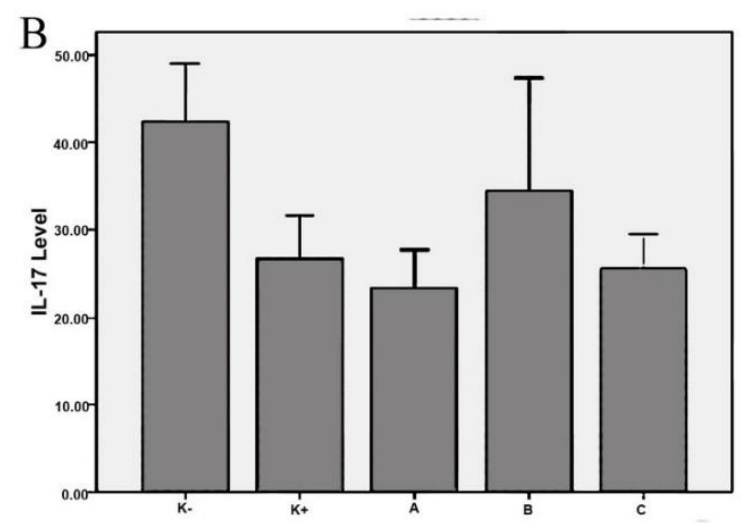

Figure 4. Representative of flow cytometric dot plot analysis between groups for Th17 cells percentages, Th17 cells were measured in the upper right quadrant expressingCD4+ IL-17A+; B) Comparison of Th17 percentage between groups;

Desensitization of dsDNA peptide increase Treg cell proliferation

The representative dot plots of Treg cells in flowcytometry analysis were shown in figure 6A. The percentages of Treg cells were measured from the cells which positively expressed CD4, CD25, and Foxp3 (upper right quadrant in the dot plot). As shown in figure 6B,
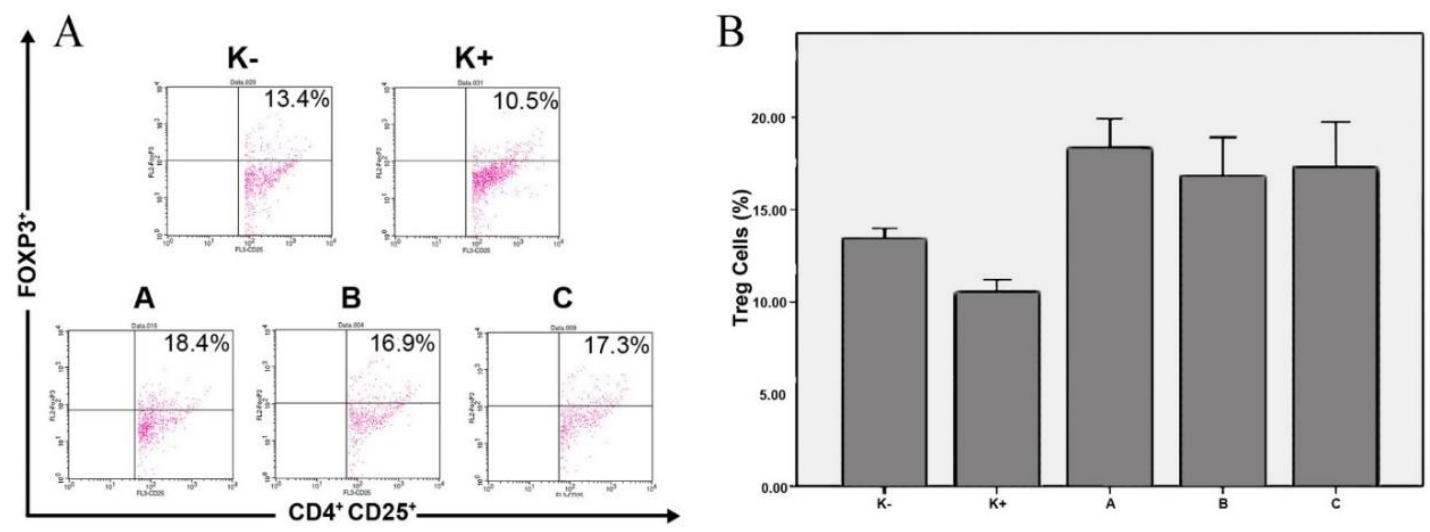

Figure 5. Representative of flow cytometric dot plot analysis between groups for Treg cells percentages, Treg cells were measured in the upper right quadrant expressingCD4+ CD25+ Foxp3+; B) Comparison of Treg percentage between groups; 
Desensitization of dsDNA increase TGF- $\beta$

level

Our investigation was to assess the ability of the dsDNApeptide to increase TGF- $\beta$ production. Serum TGF- $\beta$ levels were slightly lower in $\mathrm{K}+$ (261.02 \pm 52.26$)$ compared to K- $(335.38 \pm$ 27.80, $\mathrm{p}=0.14)$. Serum TGF- $\beta$ levels in $\mathrm{A}$
(732.43 \pm 98.69, $\mathrm{p}=0.03)$ were significantly higher and different compared to $\mathrm{K}+$. The higher levels of serum TGF- $\beta$ levels were found in B $(740.90 \pm 25.3, \mathrm{p}=0.079)$ compared to $\mathrm{K}+$. Serum TGF- $\beta$ levels in C $(382.25 \pm 96.1, p=$ 0.24 ) were slightly higher but not significantly different compared to $\mathrm{K}+$.

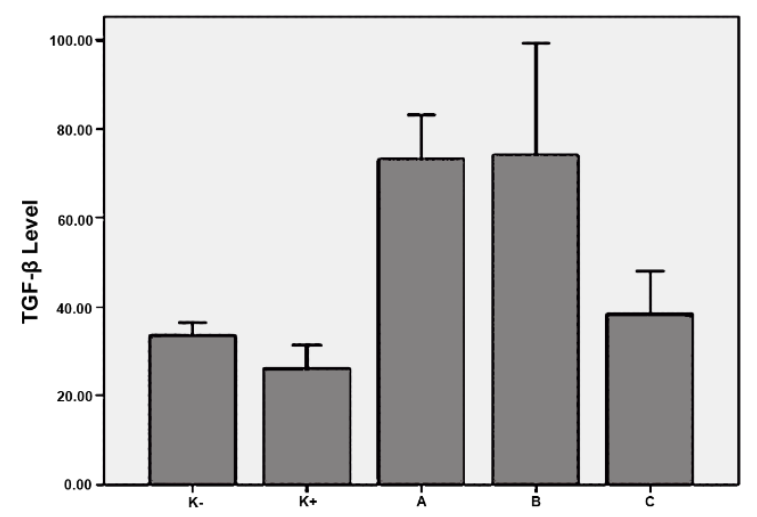

Figure 6. Comparison of TGF- $\beta$ levels between groups;

Desensitization of dsDNA peptide did not affect B-cell proliferation

Assessment of CD11 cell proliferatino was done by measurement of the percentages of plasma cell by flow cytometry assay.The representative dot plots of proliferative B cells in flow cytometry analysis were shown in figure 2A. The percentages of proliferative B cells were measured from the cells which positively

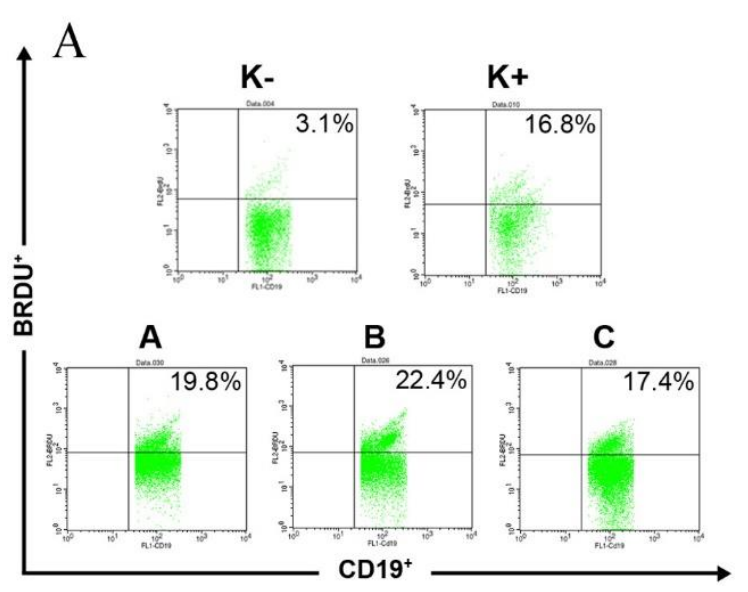

expressed BRDU and CD19 (upper right quadrant in the dot plot). As shown in figure 2B, the percentages of proliferative $\mathrm{B}$ cells in $\mathrm{K}$ group (3.08 \pm 0.38$)$ was significantly lower compared to $\mathrm{K}+(16.75 \pm 4.19, \mathrm{p}=0.006)$. However, there is no different level of proliferative B cells between group A (19.79 \pm $2.07 ; \mathrm{p}=0.602), \mathrm{B}(22.40 \pm 6.53 ; \mathrm{p}=0.456)$, and $\mathrm{C}(17.39 \pm 0.99 ; \mathrm{p}=0.624)$ compared to $\mathrm{K}+$.

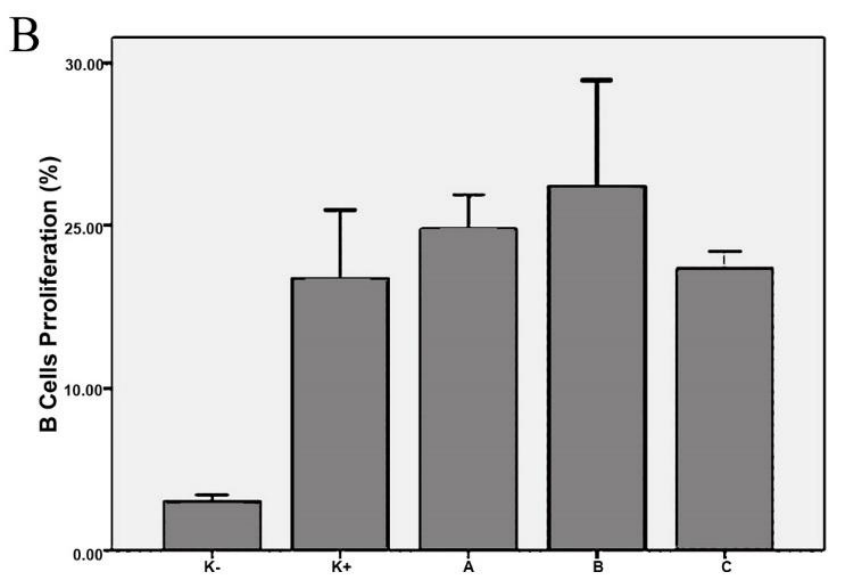

Figure 7. Representative of flowcytometric dot plot analysis between groups for plasma cells percentages, plasma cells were measured in the upper right quadrant expressing BRDU+ CD19+; B) Comparison of B cell proliferation percentage between groups; 


\section{DISCUSSION}

Recent studies conducted by Christense et al showed that dsDNA self-antigen that forms immune complex may trigger the formation of dsDNA autoantibody via activation of plasmacytoid dendritic cells in SLE patients. Normally, dsDNA self-antigen is nonimmunogenic and degraded when exposed to extracellular environment. However, when the dsDNA self-antigen is incorporated with immune complex consisting of HNP and LL37, the dsDNA self-antigens have the ability to access the intracellular compartments of plasmacytoid dendritic cells and triggers the activation of Toll-like receptors, such as TLR7 and TLR9, and stimulating the B cells to forms autoreactive antibody (Lande et al., 2011). This is a very important thing in our research to inhibit B cell activity and decrease dsDNA antibody production

Antigen-specific escalating dose immunotherapy (EDI) that has been developed for autoimmune disease is against multiple sclerosis. The subcutaneous injection of Myelin Basic Protein (MBP) are able to induce activation and function in Treg for secreting IL10 and TGF- $\beta$ cytokine that suppress the autoreactive immune cells. The use of this therapeutic method to decrease the progressivity of SLE has never been done before. Considering the excess production of abnormal cytokines plays a role in the pathogenesis of LES, it is necessary to explore further the use of EDI-Antigen-Specific Immunotherapy methods using dsDNA autoantigens for reducing the progressivity of SLE (Rifa'i et al., 2004).
The presence of abnormalities of the immune system is due to the disruption of $\mathrm{T}$ regulator cell function (Treg) in regulating the immune response and this affects the hyperactivation of various helper T cells (Th). Th cells such as Th1, Th2, and Th17 will be activated by dendritic cells (DC) and other APC cells and stimulate the occurrence of inflammatory responses, macrophage cell activation, and $\mathrm{B}$ cell lymphocyte activation (Pathak and Mohan, 2011). Similar to other studies (Elias et al., 2008; Afzali et al., 2007) we found that the pristane-induced lupus mice model had a significant increase increasing antidsDNA serum levels, the percentage of plasma cells, and B cell proliferation and decrease TReg cell compared to healthy mice

Our study demonstrated that desensitization with dsDNA peptide linked to JetPEI could supress the B and T-cell response in SLE by modulating the T-reg. We used three distinct doses to see the level of desensitization for Treg modulation and decreased level of proinflammatory cytokines. The results showed that with a dose of $5 \times 10-2 \mu \mathrm{g}, 5 \times 10-1 \mu \mathrm{g}, 5 \mu \mathrm{g}$ with 1 week interval was able to decrease autoantbody and proinfalmatory cytokine better than the other dose

The results showed escalating dose antigen spesific immunotherapy with dsDNA decreased ANA levels (30.42 vs $1.6 \mathrm{p}=0.02)$ significantly compare to positive control, decreased antidsDNA (63.4 vs $5.6 \mathrm{p}=0.03)$, decreased dendritic cell maturation ( 2.43 vs $0.75 \mathrm{p}=0.02$ ) and not significantly decreases Th17 cells ( 5,62 vs $3,62 p=0,18$ ) but the result tend to get lower. 
Increased T-reg proliferation (10.57 vs 18.38 $\mathrm{p}=0.00)$ and level of TGF- $\beta$ (261.02 vs 732 $\mathrm{p}=0.03$ ) significantly compare to control positive

The purpose of this study was to activate Treg by induced by self antigen. T-rers that are active and proliferate will be able to suppress the amount and activity of $b$ cells and cytokines for inflammation. Treg is a good cell target to restore the tolerance process in autoimmune diseases (Xu et al., 2003). Because we know that the decrease in the number and activity of

\section{REFERENCES}

Afzali B, Lombardi G, Lechler R I and Lord G M 2007 The role of $\mathrm{T}$ helper 17 (Th17) and regulatory $\mathrm{T}$ cells (Treg) in human organ transplantation and autoimmune disease Clin Exp.Immunol. 148 32-46

Elias K M, Laurence A, Davidson T S, Stephens G, Kanno Y, Shevach E M and Shea J J O 2008 Retinoic acid inhibits Th17 polarization and enhances FoxP3 expression through a Stat-3 / Stat-5 independent signaling pathway Blood 111 1013-20

Handono K, Marisa D and Kalim H 2016 Association between the low levels of vitamin $\mathrm{D}$ and Treg function in systemic lupus erythematosus patients Acta Med. Indones. 45 26-31

Kalim H 1996 Clinical features and life expectancy of systemic lupus erythematosus (SLE) Indonesian Journal of Medicine 46 383-4

Kessenbrock K, Krumbholz M, Schönermarck U, Back W, Gross W L, Werb Z,
Treg correlates with the severity of autoimmune diseases. In summary we have demonstrated for the first time that Desensitization of self-antigen dsDNA especially with dose III $(1 \mu \mathrm{g} / \mathrm{ml}, 10$ $\mu \mathrm{g} / \mathrm{ml}, 100 \mu \mathrm{g} / \mathrm{ml}$ ) was able to modulate T-Reg as a regulator immune respon and inhibit $\mathrm{B}$ and $\mathrm{T}$ cell functions to in pristane-induced lupus mice model. Elicit Dose Immunotherapy with self-antigen dsDNA may be an alternative therapy, especially for those who cannot afford or are contraindicated in steroid and monoclonal antibody therapy.

Gröne H J, Brinkmann V and Jenne D E 2009 Netting neutrophils in autoimmune small-vessel vasculitis. Nat. Med. 15 623-5

Pathak S and Mohan C 2011 Cellular and molecular pathogenesis of systemic lupus erythematosus: lessons from animal models Arthritis Res. Ther. 13 241

Rifa'i M, Kawamoto Y, Nakashima I and Suzuki H. Essential roles of CD8+ CD122+ regulatory $\mathrm{T}$ cells in the maintenance of $\mathrm{T}$ cell homeostasis $J$ Exp. Med. 2004200 1123-34.

Sakaguchi S, Sakaguchi N, Shimizu J, Yamazaki S, Sakihama T, Itoh M, Kuniyasu Y, Nomura T,Toda M and Takahashi T 2001 Immunologic tolerance maintained by $\mathrm{CD} 25+$ CD4+ regulatory $\mathrm{T}$ cells: Their common role in controlling autoimmunity, tumor immunity, and transplantation tolerance Immunol. Rev. 18 18-32 
Uyttenhove C and Van Snick J 2006

Development of an anti-IL-17A autovaccine that prevents experimental auto-immune encephalomyelitis Eur.

J. Immunol. 36 2868-74
Y 2003 CD4+CD25+ regulatory $\mathrm{T}$ cells suppress differentiation and functions of Th1 and Th2 cells, Leishmania major infection, and colitis in mice J. Immunol. $170394-9$

Xu D, Liu H, Komai-Koma M, Campbell C,

McSharry C, Alexander J and Liew F

\section{ACKNOWLEDGEMENT}

We thank Wahyudha, S.Si at Biomedic Laboratory, Brawijaya University for guiding us on flow cytometry analysis at the laboratory. This study was supported by Brawijaya University and funded by Directorate General of Higher Education (DGHE), Ministry of Research, and Indonesia. 